Dr. $\mathrm{R}$ - turned up his sleeve, pointed to the bend of the elbow, and clearly indicated that he wished to be bled. Venesection was hardly finished when a few words could be uttered. By degrees the veil seemed to be removed, and at the end of twelve hours speech was entirely restored; or, to use Prof. Trousseau's emphatic language, "tout était rentré dans l'ordre."

From time immemorial loss of speech unconnected with any other paralytic symptom must have been noticed, but it is only of late years that the diagnostic value of this symptom has been recognised and its pathology attempted to be explained. As far back as 1825 Bouillaud placed the faculty of articulation in the frontal lobes of the brain, which he considered to be the organs of the formation of words and of memory; and he stated that the exercise of thought demanded the integrity of these lobes. Then comes Dr. Dax, who places the lesion exclusively in the left hemisphere; basing his theory on the fact that when the subjects of aphasia are at the same time hemiplegic, the paralysis is always on the right side, his essay containing no less than 140 observations in support of his views. His son, Dr. G. Dax, following in the wake of his father, wrote an essay, in which, whilst confirming the theory as to the lesion being in the left hemisphere, he placed it more especially in the anterior and external part of the middle lobe. But the ne plus ultra of pathological topography was reserved to M. Broca, who defines the seat of lesion in aphasia to be "the posterior part of the third frontal convolution of the left hemisphere"! M. Broca's views are detailed at some length in the Proceedings of the Paris Anatomical Society for 1861. The question of the localization of speech being just now the subject of a warm discussion in the French Academy of Medicine, I have consulted various authors within my reach, and I find that the most conflicting evidence has been adduced with the view of connecting the faculty of articulated language with various portions of the nervous centres.

Andral has collected fourteen cases in which speech was abolished without any alteration of the anterior lobes. He cites a case of an old woman who during life had loss of speech without lesion of the intelligence, motion, or sensation, and at whose necropsy there was discovered no other lesion but softening of the centre of both hemispheres.

Romberg, who has written on this subject, mentions the case of a sailor who on being struck on the left side of the head by a loose rope at once fell down in a state of insensibility. After a quarter of an hour he recovered consciousness, but was found to have lost the use of the right half of the body and to have become speechless. Some blood was taken locally on several occasions by leeches applied behind the ear, a combination of sulphate of magnesia and tartar emetic being administered at the same time; and in three weeks from the commencement of this treatment his speech returned, and he was completely restored.

Schroeder van der Kolk's observations tend to establish a close physiological and pathological connexion between the fanction of articulation and speech and the corpora olivaria. Besides citing numerous cases in illustration of his hypothesis, he gives an $\bar{a}$ priori reason for his theory in the fact of the corpora olivaria occurring only in mammalia; and that in the higher mammalia - as the apes - they are most like those in man, but that in man they exceed in circumference by two or three times those of the chimpanzee. This to Van der Kolk is suggestive of the idea that in man they have a much more important function to discharge than in animals; and as they are connected by special fasciculi with the nuclei of the hypoglossus, he looks upon them as auxiliary ganglia of that nerve, and, as such, joined to it for the production of special combinations of movement. He also suspects that the very delicate combinations of motion in the human tongue in articulation and speech may afford an explanation of the much greater size of the olivary bodies and of their more intimate connexion with the nuclei of the hypoglossus. Van der Kolk, in support of these views, cites several cases, all showing lesion or degeneration of the olivary bodies; of which the most remarkable appears to me to be one in which there was complete inability to articulate and consequent absence of speech, without proper paralysis of the tongue, which the patient eould move, coinciding with an extremely defective development of the corpora olivaria. This great physiologist also lays great stress on a case of loss of speech oceurring in the practice of Cruveilhier, where the olivary bodies were found as hard as cartilage. To my mind this case loses wuch of its value from the fact of deglutition being impaired also.

I find less frequent allusion to this interesting subject in
British authors. Dr. Winslow, whilst admitting that cases occur where loss of the faculty of speech is clearly associated with structural change in the anterior lobes of the brain, quotes also a case of softening of the cerebellum in which speech was remarkably impaired for some time previously to death, without any perceptible lesion of the anterior lobes of the brain. Dr. Graves mentions two cases of loss of speech occurring suddenly without any previously existing or premonitory symptom indicative of nervous lesion, and unaccompanied by any other form of paralysis; but he does not touch upon the question of the pathology or treatment of this singular affection. Dr. Hughlings Jackson states that he has seen at the Hospital for Epilepsy and Paralysis forty cases of loss of speech with hemiplegia on the right side, and but one with hemiplegia on the left side. The two most recent observations that have come under my notice have a diametrically opposite pathological signification. The first is a case recorded by Mr. Holthouse in THE LANCET of April 8th, in which a lacerated wound of the scalp was followed by meningitis and suppuration of the arachnoid over the whole of the left hemisphere. There was no paralysis of limbs or face; the patient could understand what was said to him, and could put out his tongue, but there was loss of speech, and occasional convulsions on the right side of the body. The second observation is more recent still; for $I$ find in the Gaz. des Hoppitaux of April 29th that M. Languadin of Nice has reported a case of a soldier who discharged the contents of a pistol through the mouth, the ball traversing the arch of the palate in the median line. The patient lived two months, and speech was unaffected, although after death it was found that the anterior lobe of the left hemisphere was entirely destroyed by suppuration.

From a careful examination of these conflicting statements as to the pathology of aphasia, I have arrived at the following conclusions:- -

1st. That it is probable that early observers may have confounded ordinary paralysis of the tongue from mechanical injury or disease of the hypoglossus, with that loss of the memory of words and inability to give expression to thoughts which characterize aphasia.

2nd. That although further observations are necessary to place the pathology of this affection on a firm basis, the majority of cases recorded tend to favour the doctrine of localization in the left hemisphere, further investigations, however, being required to substantiate M. Broca's statement, that the lesion is limited to the posterior part of the third frontal convolution. The physiologist may ridicule the notion that an organ so perfectly syminetrical as the brain can have one hemisphere possessing a function not appertaining to the other. I must, however, remind him that this is not the only singular and inexplicable fact which physiology presents to as. Professor Trousseau, alluding to this subject, says he has never seen intercostal neuralgia except on the left side: why is this? We know nothing about it, except that it is a symptom depending exclusively on an affection of the left side of the spinal cord.

As the question of the localization of speech has now occupied the attention of the members of the French Academy of Medicine during several of their recent sittings, and still remains one of the quostiones vexate of the day, I would suggest that English observers should place on record any cases that may fall under their observation tending to determine the exact portion of the nervous centres which is affected in the loss of the faculty of speech.

Norwich, May, 1865 .

\section{ON THE TREATMENT OF HYDROCELE BY PRESSURE AFTER INJECTION.}

\section{Br JOH N C. A G N IS, M.B., F.R.C.S., ASSISTANT-SURGEON, BOYAI, HORSB GUARDS.}

WHEN a hydrocele has been operated on by the injection of iodine, or other stimulating liquid, there remains, after reabsorption of the effused fluid, more or less thickening of the tunica vaginalis and adjacent tissues. The outline of the testicle is obscured, and it continues heavy, hard, and enlarged. I never had an opportunity of ascertaining by post-mortem examination whether the internal structure of the testis itself is in any way altered. It occurred to me that the testicle affected with hydrocele might be more completely restored 
to the natural state if the enlargement and induration sequent on the injection could be dispersed by pressure applied in the way customary for orchitis. Military practice does not supply very numerous cases of hydrocele, and I offer these remarks in the hope that surgeons with a wider field for observation may try the proposed plan, and having tried it give the results of their experience to the profession. Perhaps this treatment may have been already used, but I can only say that $I$ have neither seen it employed in hospital practice nor read of it in any surgical work.

My plan is this. Having tapped the hydrocele, and injected a solution of iodine in the usual way, I wait till the tenderness has subsided enough for the patient to bear without pain a degree of manual pressure equal to that which the strapping would produce. Then I apply strapping in the way generally used for orchitis. After this the swelling sometimes diminishes so fast that the strapping has to be re-applied every second day.

I am disposed to think that the earlier the strapping is applied the better, provided the inflammation have subsided enough for it to be done without pain. The safest indication seems to be the degree of pain given by grasping the testicle gently.

Case 1.-Private J-Hydrocele tapped on Feb. 8th, 1864, and a pint of fluid let out. Injected with one part of tincture of iodine to two of water. Strapping applied on the seventeenth day, and repeated every second day. Discharged on the thirty-seventh day. There was then, and is now, no difference at all in the size of the testicles.

CAse 2.-Corporal $\mathbf{H}-$ - Testicle strapped about three weeks after injection. Treatment lasted about six weeks, with the result of restoring the testicle to very nearly its natural size. He has left the regiment, and I cannot give the precise dates of the treatment, but I have recently learned that he continues well.

Case 3.-Mr. H- Hydrocele tapped on March 15th, 1862, and eight ounces of fluid drawn off. At the patient's desire it was not injected. On the third day it was strapped. The strapping had to be discontinued on account of the patient's skin being extremely delicate and irritable, but the cure was, and is, complete.

\section{di}

OF THE PRACTICE OF

\section{MEDICINE AND SURGERY IN THE}

\section{HOSPITALS OF LONDON.}

Nulla autem est alia pro certo noscendi via, nisi quamplurinas et morborum et dissectionum historias, tum aliorum, tum proprias collectas habere, et inter se comparare.-MorgagNi De Sed. et Caus. MLorb., lib. iv. Procemium.

\section{UNIVERSITY COLLEGE HOSPITAL.}

HAIF-PIN EMBEDDED IN THE BLADDER AND SOFT PARTS WITHIN THI PELVIS; REMOVAL BY THE HIGH OPERATION; SUDSEQUENT FATAL PERITONITIS.

(Under the care of Mr. Henry Thompson.)

Is February, 1863, we recorded an instance of removal of a hair-pin from the bladder of a girl with success by $\mathrm{Mr}$. Hilton, at Guy's Hospital (vide Tre LANCET, vol. i. 1863, p. 235); and, in some remarks made at the time, we referred. to other examples which had occurred in the hospitals of London, but more especially at St. George's and King's College Hospitals. In all these cases the patients were girls, and the hair-pins were mostly of thin wire. Differing from any of these is an example which we now publish, wherein the wire of the pin was so thick and stiff as to resist the means first employed to remove it, and necessitating the performance of the high operation, as if for stone, to extract it. The immediate result was quite satisfactory, for we saw the girl up and about the wards apparently in excellent health, when, unfortunately, suppuration took place in the walls of the pelvis, and fatal peritonitis carried her off: Although young, the patient was large and womanly in appearance.

A girl, aged thirteen years, had the misfortune to introduce a hair-pin through the urethra into the bladder a few days before her admission. She resided upwards of 150 miles from London. Having been examined by two medical gentlemen, and the presence of the pin ascertained, and also that it had assumed a fixed position, it was determined to send her up to the care of Mr. Henry Thompson at University College Hospital. She was admitted on the 6 th of January last. The long railway journey had caused little suffering; and neither the pain nor the frequency of passing water was severe. The urine was a little turbid, but not much so; the appetite and general condition were good. On the 9 th $\mathrm{Mr}$. Thompson sounded her, and found such a body as that described lying across the bladder. All further examination was deferred until she should be placed under the influence of chloroform for its removal. Meantime the patient furnished three precisely similar pins for experiment. They were made of unusually stout wire. On applying to one of them the modern French instrument which so ingeniously draws up into its shaft any wire it lays hold of, whatever the position in which it is seized, the pin was found too rigid and unyielding to be so managed. On applying great force the instrument broke. It was, however, repaired and strengthened; still the same result occurred. It was obvious that the instrument could not be relied upon in the bladder for this case.

On the 11th she was placed on the operating table, under chloroform. Mr. 'Thompson introduced a small lithotrite, and, seizing the pin, found it firmly fixed; it yielded only slightly on traction, and could not be rotated on its axis by any force which it was allowable to employ. She was then examined by the vagina and rectum by Mr. Thompson and by his colleague Mr. Erichsen, and the pin was found-apparently its points and lower part-- between these passages and the wall of the pelvis on the left side, while the head of the pin was distinguishable beneath the parietes of the abdomen above the. pubes. After consultation, it was decided to perform the high operation, opening the bladder immediately above the pubic symphysis, This Mr. Thompson proceeded to do, Mr. Erichsen holding a silver catheter in the bladder with its point resting. against the upper fundus, as a guide to the position of the organ. After some little difficulty in entering the bladder, from the protrusion of the catheter through a small orifice, the operator's finger was introduced, the pin felt, and easily removed by a pair of dressing forceps. A No. 12 gum-elastic catheter was cut short and tied in the bladder by the urethra, and the wound dressed with wet lint.

She suffered much pain in the evening, and took full doses of the sedative solution of opium, the urine passing well by the catheter.

Tan. 12th. - She is tolerably comfortable; no tenderness of belly; takes fluid nourishment freely. Pulse 110, soft. Dressings and catheter remain.

13th.-Going on well, but complains much of the presence of the catheter, which has therefore been removed. Continues: the opiates.

14th.- Urine comes up freely through the wound; catheter again placed in the bladder by the urethra. To continue opiates.

15th. - Pain in the belly, and some diarrhoea. Hot fomentations to be applied. Opiate to be increased, and to have warm: chalk mixture.

16th.-Much relieved; pain in the belly gone: was evidently due to flatulent distension. Has taken custard pudding with relish to-day.

The catheter was dispensed with on the 18th. After this she gradually improved, and notes were only occasionally taken of her case.

Feb. 6th. -The opening has entirely closed; no urine passes: except by the urethra. She holds her water three hours; has no pain; eats and drinks well; and goes about all day. She continued so during the next week, playing about the ward; and was to be sent home to the country in a day or two as perfectly convalescent.

13th. - In the evening, while actively occupied as usual, she felt a sudden pain in the abdomen, and went to bed.

14th.-Mr. Thompson saw her. She was suffering severely, and her prostrated condition left little doubt that something had given way in the belly, and had occasioned symptoms of peritonitis. She gradually grew worse, and died on the 16 th.

At the antopsy on the following day it was discovered that an abscess had slowly formed between the site of the wound and the bladder, and had extended beneath the peritoneum 